\title{
A los siete años de la masacre del Naya: la perspectiva de las víctimas
}

\section{Myriam Jimeno, Ángela Castillo e Daniel Varela}

\section{(2) OpenEdition \\ 1 Journals}

Edição electrónica

URL: http://journals.openedition.org/aa/958

DOI: $10.4000 /$ aa.958

ISSN: 2357-738X

Editora

Programa de Pós-Graduação em Antropologia Social (UnB)

\section{Edição impressa}

Data de publição: 1 dezembro 2010

Paginação: 183-205

ISSN: 0102-4302

\section{Refêrencia eletrónica}

Myriam Jimeno, Ángela Castillo e Daniel Varela, «A los siete años de la masacre del Naya: la perspectiva de las víctimas», Anuário Antropológico [Online], v.35 n.2 | 2010, posto online no dia 04 novembro 2015, consultado o 28 abril 2021. URL: http://journals.openedition.org/aa/958 ; DOI: https:// doi.org/10.4000/aa.958

\section{(c) (i) $९$}

Anuário Antropológico is licensed under a Creative Commons Atribuição-Uso Não-Comercial-Proibição de realização de Obras Derivadas 4.0 International. 


\title{
A los siete años de la masacre del Naya: la perspectiva de las víctimas
}

\author{
Myriam Jimeno \\ Universidad Nacional de Colombia \\ Centro de Estudios Sociales CES \\ Ángela Castillo \\ Universidad Nacional de Colombia \\ Centro de Estudios Sociales CES \\ Daniel Varela \\ Universidad Nacional de Colombia \\ Centro de Estudios Sociales CES
}

\section{Presentación}

Cuando en abril del 2008 se cumplió el séptimo aniversario de la masacre llamada del Alto Naya, situado en las montañas del sur occidente colombiano, una pequeña comunidad de familias indígenas y de otros orígenes, víctimas de la masacre, preparó un acto de conmemoración. Sobre esta conmemoración, entendida como una puesta en escena, nos detendremos en el texto, pues nos permite una discusión sobre los mecanismos y procesos en los que la política cultural alienta la recomposición emocional y política después de un hecho de violencia de gran magnitud. La narrativa escénica pone de presente ciertos énfasis, matices y juegos de sentido, así como la forma en que las personas los emplean para recobrarse como sujetos y para crear comunidades emocionales que trasciendan sus fronteras étnicas y culturales.

La conmemoración transcurrió en condiciones interculturales dada la presencia de muy diversos agentes sociales y en correspondencia, la narrativa escénica no se limitó a ser un ritual interno de la comunidad. Si bien en estos casos "la cultura se convierte en un pilar básico de la acción colectiva” (Dietz, 2007:39), la audiencia era demasiado heterogénea. Esto suponía exigencias para que el sentido y los recursos simbólicos fueran comprensibles y pudieran ser compartidos por unos y otros sin perder su sello de "indígena", identidad a la que se adscribe la mayoría de la comunidad. El resultado de ese desafío fue un ejercicio de política intercultural en el que descansó la capacidad de esta comunidad para ofrecer una versión compartida de los hechos y tender lazos afectivos entre los muy diversos asistentes. 


\section{REPUBLICA DE COLOMBIA}
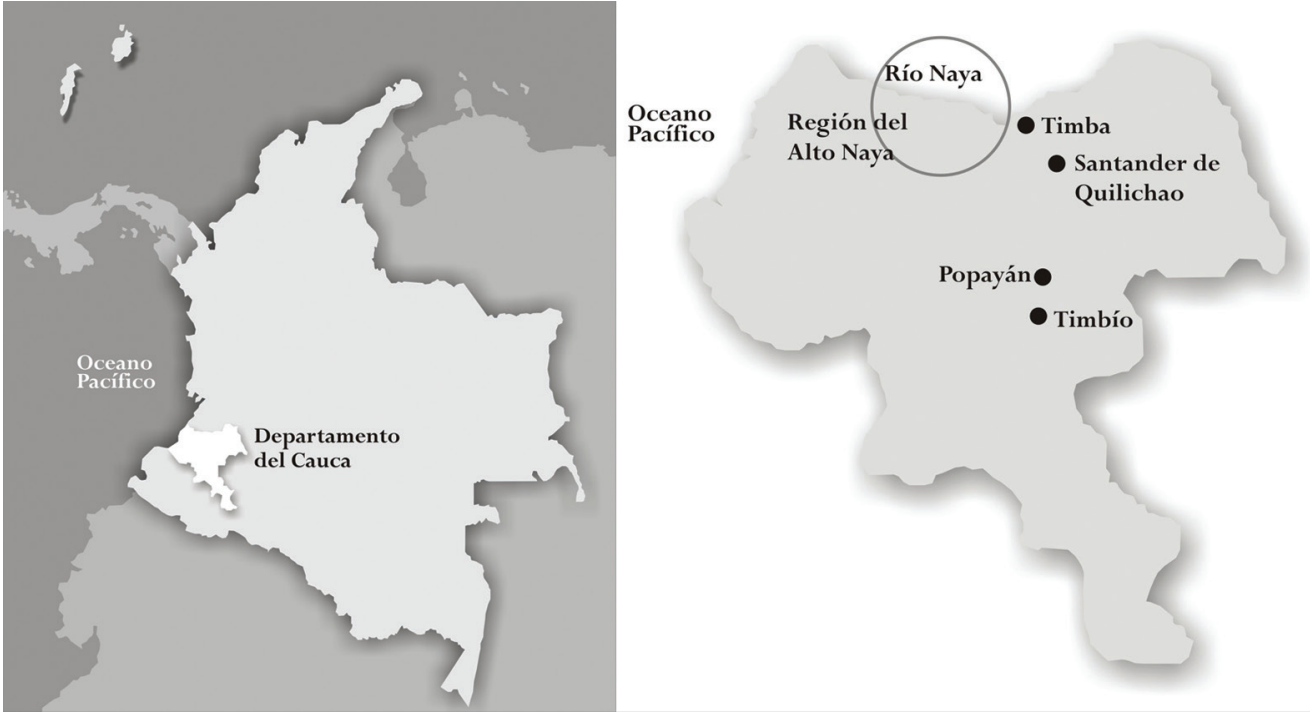

\section{Una masacre anunciada}

La región del río Naya ${ }^{1}$ (véase Mapa) es hogar de comunidades negras, indígenas y campesinas que arribaron a la zona en distintas oleadas de doblamiento. La gente negra llegó como mano de obra esclavizada junto con el establecimiento del distrito minero de Barbacoas a finales del XVII; ocupan hoy las partes más bajas de la región (Díaz, 1994:85; Mosquera \& Aprile, 2001). La parte baja del río Naya, justo en su desembocadura sobre el océano Pacífico, la habitan desde tiempos prehispánicos núcleos de la etnia eperara siapirara. En los años cincuenta del siglo XX llegaron a la parte alta del Naya familias de indígenas Nasa que huían de la violencia y la falta de tierras en el Cauca. Además, entre los años ochenta y noventa pasados, las oportunidades económicas de la producción de coca en esa remota zona, animaron a ensayar vida a campesinos y pequeños comerciantes. Este heterogéneo panorama étnico le imprime a la región del Naya condiciones particulares de contacto intercultural.

Desde los años 1990, las guerrillas de las Fuerzas Armadas Revolucionarias de Colombia (FARC) y del Ejército de Liberación Nacional (ELN) se disputaron el dominio de la región. Los unos estaban interesados en el control del naciente mercado de coca y ambos en del territorio, ideal como zona de refugio. En el año 2000 el ELN llevó a cabo dos secuestros en la ciudad de Cali, muy connotados por su carácter masivo: en uno tomó a todos los asistentes a un servicio religioso en una iglesia de público mayoritariamente adinerado (Iglesia La María); en el otro capturó a los de un restaurante en las afueras de la ciudad (Kilómetro 18, carretera 
al mar). Se supo que los secuestrados fueron conducidos por montañas de difícil acceso - los Farallones de Cali - hasta el Alto Naya. La retención de estas personas culminó con la negociación entre el grupo insurgente, el Estado y los familiares de los secuestrados. Y desde entonces corrió el rumor de que la población local conocía del secuestro o apoyaba de alguna forma a la guerrilla.

Durante los días 10 al 13 de abril del 2001, días de las celebraciones religiosas de la Semana Santa católica, 500 hombres armados de las AUC bloquearon el acceso y recorrieron la región. Incendiaron casas, dieron muerte al menos a cerca de 40 personas $^{2}$ y amenazaron y obligaron a huir a muchos más. Dicen sus víctimas que fue una intervención punitiva anunciada desde el secuestro y algunos afirman que la alentaron también algunos interesados en abrir la zona a la explotación minera y a mayores comerciantes. Ya desde el año 2000 las AUC eran fuertes en la zona plana del norte del Cauca y controlaban el acceso terrestre al Naya. A raíz de la masacre, unas 3.500 personas $^{3}$ huyeron hasta pueblos en las tierras planas-Timba, Santander de Quilichao, Tóez, principalmente (Defensoría del Pueblo, 2001). Permanecieron meses hacinados en los varios centros de acogida, pero paulatinamente la mayoría retornó al Naya.

No obstante, 50 familias, en su mayoría indígenas Nasa y algunos campesinos, se negaron a volver al Naya por las precarias condiciones económicas y de seguridad. Emprendieron desde entonces la tarea de crear una nueva comunidad, apuntalados primero por la organización Asociación de Campesinos e Indígenas Desplazados del Naya - ASOCAIDENA y más luego por la creación de un cabildo de indios. Una de las acciones fue demandar la dotación de tierras mediante una acción de tutela. Mientras, persistieron en los refugios por cerca de cuatro años. En el año 2004 tuvo éxito la acción jurídica y obtuvieron la finca La Laguna, ubicada a pocos minutos de la ciudad de Popayán. Una vez allí, conformaron la nueva organización, esta vez siguiendo los viejos moldes de origen colonial hispánico, el cabildo de indios, que ha sido la unidad básica del movimiento y la organización indígena contemporánea en la región andina colombiana (véase Rappaport, 2005; Jimeno, 2006). Pronto lo afiliaron a la organización regional indígena Consejo Regional Indígena del Cauca (CRIC). Permanecen en La Laguna y mantienen las dos organizaciones. Protegidos por medidas cautelares, algunos hacen parte de quienes testimonian dentro de la Ley de Justicia y $\mathrm{Paz}^{4}$ contra el jefe paramilitar Hever Veloza, "HH”, hoy extraditado a los Estados Unidos.

\section{5 de Abril 2008. Siete años después}

Son las tres de la mañana y se ilumina la casa de Lisinia, indígena Nasa, donde estamos alojados en La Laguna. Todos se despiertan poco a poco con los ruidos - voces, perros, un gallo, la infaltable TV - que vienen de la casa vecina, la de la hermana de Lisinia. Cuando los vecinos encienden la luz, la casa de Lisinia también se ilumina con el brillo verdoso que proyecta la tela plástica - verde - que hace de 
pared de las casas. La mayoría de las viviendas en La Laguna están elevadas varios centímetros sobre el suelo, lo que de seguro rememora la construcción que tenían sus casas en las tierras cálidas del Naya. Están hechas de tablones aserrados y una sencilla estructura en madera recubierta de la tela plástica, verde. Por ésta, además de la luz, se cuela el viento y los ruidos de los vecinos. Es que ahora, dicen los de la "comunidad”, viven “amontonados", no como cuando vivían en el Naya, en fincas separadas por kilómetros. Ni modo, habrá que levantarse, aunque aún es temprano para aguardar las chivas $^{5}$ que vendrán a recoger a quienes vamos para el pueblo de Timba a la conmemoración.

Timba (municipio de Buenos Aires) está en un recodo de las tierras planas y es un pequeño poblado, en su mayoría de población negra; es una de las bocas de entrada al Naya. Allí se hará la séptima conmemoración de la masacre, como fue acordado entre los afectados. Se encontrarán quienes volvieron al Naya, los que quedaron en Santander y en otros pueblos y los de la finca La Laguna, ahora llamados Kitek Kiwe o Tierra Floreciente en lengua nasa yuwe. También se escogió Timba porque el alcalde está interesado en que se convierta en uno de los casos seleccionados por la Comisión Nacional de Reparación ${ }^{6}$ para un proyecto piloto de atención a víctimas de la violencia. Sería un plan de inversión en obras comunales y dinero a cuotas para la reparación individual. Los dirigentes de Kitek Kiwe, Lisinia entre ellos, son escépticos sobre este plan y no admiten que implique la renuncia a la reparación colectiva. Lisinia insiste en que deben estar presentes en la conmemoración y dejar allí su sello peculiar: manifestar su punto de vista sobre "la reparación, la verdad y la justicia para con las víctimas”. Por eso, varios de Kitek Kiwe viajaron desde días antes para llegar a acuerdos con el alcalde, con los representantes de las asociaciones de pobladores negros y los de las juntas comunales. Reiteran la necesidad de mantener independencia y no dejar transcurrir el acto reducido al anuncio del programa oficial de reparación.

En Kitek Kiwe la mayoría de la población tiene origen Nasa; había llegado al Naya, ellos o sus padres, desde los años cincuenta (Caicedo et al., 2006). Hoy son 249 personas con una muy alta proporción de jóvenes y niños, integrados en el Cabildo Nasa Kitek Kiwe, en el que tienen cabida varias familias "mestizas" y un par de indígenas guambianos. La adscripción étnica indígena que revelan la creación del cabildo y el nombre del grupo, no obstan para mantener la comunicación, a veces tensa, con las organizaciones comunales campesinas y afro descendientes de quienes retornaron al Naya. ${ }^{7}$

La política cultural de los Kitek Kiwe invita a la discusión sobre las acciones de inter y multiculturalidad, denominaciones que suponen formas distintas de encarar la diferencia cultural y de resolver los conflictos que emergen de los reclamos por el reconocimiento del derecho a la diferencia. Jean Jackson (2005) discute que en Colombia, como en otros países de América Latina, la movilización 
indígena desde los años setenta pasados supuso un conjunto de reformas jurídicas. Pero, sobre todo, implicó la apelación a la "cultura" y a los derechos culturales (Jackson, 2007; véanse Rappaport \& Gow, 1997; Jimeno en prensa). La búsqueda india de un mejor lugar en las sociedades nacionales latinoamericanas ha traído un activo proceso de producción cultural que no apunta tan sólo a obtener legislación favorable, sino ante todo crea imágenes y formas discursivas en las que puedan reconocerse también los no indios (Rappaport, 2005; Jimeno en prensa). Esta producción es el resultado de una política cultural, parte activa del indigenismo en el sentido que le da Alcida Ramos a este término (1998). Es decir, como un edificio ideológico en cual se expresan y del que participan no sólo los indios y sus organizaciones, que por lo demás tienen las más variadas experiencias con el mundo no indígena, sino intelectuales y activistas no indios, en un proceso complejo y a veces conflictivo (Rappaport, 2007, 2005; Jackson, 2005; para otra apreciación, véase Chávez, 1998).

Michel Wieviorka (2003:28, 29) subraya que el término multiculturalismo designa una política inscrita en las instituciones, el derecho y la acción gubernamental, apunta a una política "desde arriba". A diferencia, la interculturalidad es horizontal y da cuenta de las relaciones entre culturas diferentes en condiciones de respeto mutuo. En contraste con Wieviorka, argumentamos que para dar lugar al multiculturalismo como acción institucional de ampliación de la democracia, es necesaria una acción con deliberada orientación intercultural; que busque comunicar esferas sociales y campos culturales distintos en pie de igualdad. Una acción intercultural hace posible formas de multiculturalismo que no lleven a que la afirmación de la diferencia cultural conduzca a la opresión o al ataque extremista a otros, como lo recuerda Kymlicka (1996), sino al abordaje explícito de las necesidades y aspiraciones de las minorías étnico culturales (Ibid.). Tal vez así sea posible la comunicación que permita un "multiculturalismo emancipatorio" como lo llama De Sousa Santos (2002).

Justamente la conmemoración de los siete años de la masacre puede verse como una acción intercultural, pues acude a un conjunto dispar de elementos, de origen heterogéneo, irreductibles a un simulacro y tampoco a su uso meramente instrumental, pese a sus simplificaciones. El uso instrumental o el uso estratégico de recursos culturales con fines personales, como lo han discutido Marshall Sahlins (2001) y desde una perspectiva diferente Jeffrey Alexander (2006), es al mismo tiempo funcional, operativo y deliberado, tanto como estructural. Esto es así porque las personas están vinculadas a los dispositivos culturales mediante su capacidad auto reflexiva, lo que da lugar a ciertas manipulaciones, pero también están ligadas por medio de profundos lazos afectivos y de identificación personal. La conmemoración, vista como puesta en escena, puede entenderse como proceso social por el cual actores sociales les exhiben a otros el significado de su situación 
social (Alexander, 2006:32). Para Alexander, la puesta en escena es un acto ritual polisémico, que no sólo evidencia y expone algunos de los más caros valores y orientaciones culturales del grupo, sino que muestra los usos que las personas les dan de manera deliberada y en determinados contextos. Pero Alexander se queda corto para este caso, pues supone que debe existir un campo común de entendimiento. Aquí la selección de ciertos marcadores de identidad étnica por los de Kitek Kiwe es, en vez de separación, posibilidad de encuentro en la diferencia.

Pensamos también que esta puesta en escena permite ver que la acción subjetiva y la colectiva son partes de una misma formación cultural. Más aún, hay continuidad entre la interpretación emocional y personal de los sucesos - el dolor, el miedo, la rabia personales - y la acción pública. Remarcamos así la interrelación y no la discontinuidad de los procesos subjetivos y los sociales. Unos y otros son los ingredientes de la producción simbólica y de la comunicación de sentido que operan como marcos interpretativos, puesto que se convierten en relatos públicos de una situación peculiar, y esto es lo que permite alcanzar una interpretación compartida de los sucesos de violencia y del dolor subjetivo que han ocasionado (Jimeno, 2004).

Pero hay que levantarse, las chivas van a llegar, ¡no más digresiones!

\section{A las chivas}

Todos saben en Kitek Kiwe que hay que levantarse temprano ese 25 de abril (2008) y ocupar las chivas antes de las 5 AM. Nada se ha dejado al azar. Los miembros del cabildo y de la dirección de la Asociación de Campesinos e Indígenas Desplazados del Alto Naya han realizado varias reuniones de preparación con una distribución minuciosa de las tareas. Está definido quienes hablarán, qué dirán, y en qué momento de la reunión. Se afanan por buscar las fotos ampliadas de algunos de los muertos en la masacre y en alistar los pendones recién hechos para la ocasión. Por último, ya llegaron a acuerdos con las otras organizaciones, de quienes volvieron al Naya, las de comunidades negras, el CRIC, las autoridades locales. También los niños y uno de los maestros han trabajado arduamente en el sociodrama que les propusimos nosotros presentar.

Una chiva está destinada a los niños de la escuela, el Centro Educativo Elías Trochez, llamado así en memoria del gobernador del cabildo "La Paila" del Alto Naya muerto por el ELN, pocos meses antes de la masacre. ${ }^{8}$ Viajarán 45 niños de los 74 que componen el Centro, junto con los cinco maestros y los antropólogos, que ya somos seis, sumados los dos estudiantes que hacen su trabajo de grado para la Universidad del Cauca y Pablo, el cineasta encargado de la realización de un video documental para nosotros. Así que hay que levantarse, buscar el agua en la instalación de "baño" distante unos metros de las casas y estar dispuestos a la hora convenida. 
Cuando salimos de la casa, ya el patio estaba lleno de niños en algarabía, con los bastones de mando, símbolo de la autoridad de los cabildos del Cauca, colgados a través del pecho o en la mano. La guardia indígena, una organización que data de unos pocos años atrás como respuesta defensiva ante las acciones de los grupos armados, compuesta en su mayoría por hombres jóvenes, se apresuraba, bastón de mando a mano, a indicarnos que debíamos concentrarnos en la pequeña explanada frente a las viejas, que no antiguas, casas de la hacienda de La Laguna. Éramos unas 130 personas. La guardia indicó que todos debíamos registrarnos en listados ya dispuestos que sostenían varios miembros del cabildo. La operación se realizó con rapidez sorprendente mientras las chivas entraban a la finca, a todo pito, con pocos minutos de retraso de la hora convenida. '¡Los adultos en las ventanas!', indicaron los miembros de la guardia.

5:30 AM. Las chivas salieron de la finca como llegaron, a pleno pito, como para que nadie las ignorara. Como aún no amanecía, iban con las luces internas encendidas, círculos, flores y estrellas rojas, verdes, iluminaban intermitentes el colorido y abigarrado decorado interior que las hace tan características como para ser emblema patrio. Un gran letrero separaba al chofer de los pasajeros: "Sonido lasser (sic)".

Con el día apreciamos la cabina, adornada como un altar popular, con visillos rojos y espejos sobre fondo blanco esmalte que rodean una imagen de Cristo. Yerson, el joven maestro a cargo del sociodrama, trajo música para el camino; no olvidaba sus habilidades en el Naya como el disk jockey en una reconocida discoteca en la región. Se lo conoce por su gusto por la música popular, en especial cumbias villeras, baladas, regatón y rancheras, y por la especial entonación de su voz, su postura corporal y una marcada vocación histriónica. Yerson no es indígena, es de Santander de Quilichao y emigró al Alto Naya en busca de mejor suerte, dos años antes de la masacre. Se ha integrado a la comunidad que surgió después de la masacre por la vida en común en el desplazamiento.

A las 10:30 de la mañana llegamos a Timba. Yerson se puso de pie y a una señal suya, los niños empezaron a corear consignas: ‘"se vive, se siente, el Naya está presente”!; ‘ni perdón, ni olvido”!, gritos que acompañaron la entrada de las chivas, a todo pito. Recorrieron el pueblo hasta el parque central, donde estaba el recinto para la conmemoración: el edificio de la plaza de mercado. Los niños se formaron a la entrada y al frente algunos jóvenes sostenían el estandarte de fondo amarillo en el que se leía: "Cabildo indígena Kitek Kiwe - Asociación de Campesinos e Indígenas Desplazados del Alto Naya”. El estandarte lo acordaron unas noches antes, en reuniones de preparación, junto con las enormes pancartas en cuyo diseño participaron activamente Daniel y Ángela, en conocido gesto de apoyo con la "causa indígena". Los niños, en coro, gritaron desafiantes contra "Uribe". Entraron en hilera por el centro del salón, agitando sus bastones encintados: “iSe vive, se siente el Naya está presente!”. En un gesto no previsto por los 
organizadores del evento, mientras cantaban, subieron directo al escenario. Los jóvenes de Kitek Kiwe, por su parte, desplegaron las pancartas de varios metros que opacaron por completo a los pequeños letreros en papel de las asociaciones de comunidades negras y algunos pocos globos blancos: "Los familiares de las víctimas del Naya exigimos Justicia, Verdad, Reparación y Derecho a la no Repetición”. "Por la vida y la dignidad de los pueblos. Ni perdón, Ni olvido. Castigo a los actores materiales e intelectuales". Al lado lucían el estandarte rojo y verde del CRIC y una bandera de Colombia.

Los niños miraron al público, entre 800 y 1000 personas, principalmente gente negra y algunos indígenas y campesinos, apretujados en un amplio salón. La mesa directiva estaba compuesta por funcionarios estatales del la Comisión Nacional de Reparación, de la Organización Internacional para las Migraciones, de la Vicepresidencia, de la Defensoría del Pueblo, el alcalde de Buenos Aires, el delegado de la OEA y dirigentes de los consejos comunitarios del Proceso de Comunidades Negras y de otras organizaciones locales de maestros. Quedaron en silencio, ubicados abajo del escenario. Arriba, los niños esperaban su oportunidad: entonaron el himno de Colombia, pero lo hicieron en lengua nasa yuwe, en alto los bastones encintados. Un rumor recorrió el salón y todos se pusieron de pie. Siguieron con el himno del CRIC, también en la lengua indígena. Después de los himnos, los niños se sentaron en la tarima a la espera del momento indicado para presentar el socio drama que habían preparado. La agencia de noticias Caracol TV, que trasmitió en directo todo la ceremonia, se apresuró a filmarlos. Lo mismo hicieron camarógrafos y fotógrafos de medios de comunicación de la región. Tampoco nosotros nos quedamos atrás y filmamos la escena. Pero antes de seguir adelante es preciso detenerse en el sociodrama compuesto por los niños.

\section{Ensayos}

Es 21 de abril, lunes, cinco días antes de la conmemoración. La casa de Lisinia se pone en movimiento desde las 5 AM. Ella enciende la luz para preparar el desayuno de las niñas, su hija y las de Carlos Alberto, su compañero guambiano, pues deben ir a la escuela, unas en la comunidad, otras en el pueblo cercano. Carlos Alberto está en la comunidad hace un año y medio junto con su hermano. Son guambianos, pero vivieron desde niños, y hasta hace poco, en el resguardo indígena nasa de Toribío, norte del Cauca, a donde emigraron sus padres. Temprano pasan por la vía Jorge y Enrique, el uno presidente de la Asociación de Campesinos e Indígenas ASOCAIDENA, el otro gobernador del cabildo: "vamos para el norte [del Cauca], y si Dios quiere, volvemos en la noche". Ninguno de los dos se autodefine individualmente como indígena, pero ambos crecieron en medio de las comunidades del norte del Cauca y en los dos casos uno de sus abuelos fue nasa. Su definición individual no es obstáculo para que pertenezcan a la dirección del Cabildo Indio Kitek Kiwe. 
Durante el día Lisinia va y viene entre las labores domésticas y el reburujar entre cajas de cartón y pilas de papeles en busca de las fotos de algunos de los muertos en la masacre, que sólo aparecen a medio día, demasiado maltrechas, pues fueron parte de una pancarta fabricada para que Lisinia la portara en Bogotá, en la marcha del 6 de Marzo de 2008 por las víctimas del paramilitarismo. Lisinia está afanada. Daniel se encarga. Busca en el computador del cabildo las fotos, las copia en una memoria digital y va hasta un café Internet en el pueblo cercano, las envía a Popayán para su reproducción y luego las recoge, pues deben estar exhibidas durante la conmemoración.

En la mañana, Yerson, el maestro, llama para ensayar el sociodrama. El sociodrama, como dijimos, fue ideado por nosotros como parte de los instrumentos de investigación. Propusimos representar el suceso de violencia en tres escenas: la primera, la huída ante la masacre y las amenazas; la segunda, la vida en los campamentos en Timba y Santander, y la final, la reorganización en la finca La Laguna. Les pedimos representar acciones, pensamientos y sentimientos. La idea inicial fue que tres sectores de la comunidad la escenificaran, mujeres, niños y hombres adultos. Sin embargo, lo que tuvo eco fue la participación de los niños, y el Cabildo decidió que era importante presentar el sociodrama en la conmemoración.

El salón principal de la escuela está localizado en la parte central del caserío, en una zona alta, junto a las oficinas del Cabildo. Cuando subimos al salón ya se apiñaban allí los niños. Niños y niñas entre los 10 y los 15 años. Un público variado de madres y otros niños, de los otros profesores y algunos miembros del Cabildo entraban, miraban, salían. Decidimos filmar el ensayo e intervenir lo menos posible. También llegaron Mayra y Carlos Andrés, quienes hacen allí su trabajo para el grado como antropólogos en la Universidad del Cauca.

Yerson está de acuerdo en dividir la puesta en escena en tres actos. Él comenzó por pedirles a los niños seleccionados, alrededor de unos 20, que contaran lo que sabían y sus recuerdos más importantes. Algunos no recordaban los sucesos o no los vivieron, pero conocían bien el relato de boca de sus padres y de otros. Con base en estos recuerdos y oídas, tejieron la historia y determinaron personajes y escenas. Los personajes seleccionados fueron tres familias: una compuesta por padre, madre e hijos; otra de abuela y su nieta y una pareja. Además, incluyeron a un mensajero, un comerciante, un te'wala, ${ }^{10}$ un afrodescendiente, un grupo variado de trabajadores, un raspachín ${ }^{11}$ y los paramilitares o "paracos". Pero en el curso del ensayo decidieron reemplazar a los paramilitares por un personaje llamado "la muerte". Dijeron que era mejor así porque no querían personalizar, sino representar la "violencia”, además de que "los protagonistas deben ser las víctimas y no los grupos armados”. Por su parte, el raspachín provocó, como veremos, una gran discusión. 
Ensayaron durante todo el día a lo largo de tres días, con pequeños recreos, entre comentarios y exclamaciones de aprobación o disgusto del público. A veces Daniel y Ángela fueron interpelados para armar un diálogo... pero poco dijeron. Los niños ensayaron con los pupitres y utilería de ollas, azadones, palas, matas de plátano y ropa que trajeron de sus hogares, a veces entre risas y gritos, otras veces con cierto tedio.

El primer acto lo dividieron en tres escenas: la vida en el Naya y la noticia del ataque, la huída y la llegada a los campamentos de refugiados. La primera escena mostró la vida cotidiana en el Naya: agricultores, un comerciante, un arriero, un indígena que masca coca, un minero negro y un raspachín de coca trabajan en labores del campo. Llega un personaje vestido de negro, la "muerte", que los siega uno a uno, dejándolos muertos a su paso. Pero una persona la esquiva y escapa: el mensajero. Las familias duermen hasta que el mensajero las despierta a gritos: “¡son los paramilitares, vienen los paramilitares, tienen que salir rápido!!”. Cada familia reacciona de forma distinta. Una se apresura y salen tan sólo con las ropas que tienen puestas, otra se niega a creer y se aferra a permanecer y la tercera lucha por seleccionar qué llevar: el protagonismo lo tiene una niña que no quiere dejar a su muñeca y se enfrenta con su abuela por eso. El te'wala, un hombre "mayor", habla con las familias que se rehúsan a salir, les dice que es mejor huir, que no es bueno quedarse, que "esas personas no traen buenas intenciones".

Luego muestran el correr por un camino; tienen miedo, corren por la trocha, se tropiezan, algunos caen. Por el camino encuentran personas muertas y los adultos les tapan la cara a los niños para que no los vean. Algunos van descalzos y para poder caminar deciden recoger las botas que llevaban los muertos en el camino. Es de noche, muchos más se apuran, muestran miedo, fatiga, angustia. Entra un hombre, exclaman, “iEnrique Güetio!”. ${ }^{12}$ Él preguntó con angustia “QQué ha pasado, qué ha pasado?”.

Sobre la escena de muerte aparecen camarógrafos y periodistas. Yerson les pidió entonces a los actores de estos personajes que mostraran aire festivo y despreocupado y a Daniel, que practicara con el supuesto reportero de televisión un guión según el cual el periodista buscaba forzar la entrevista a los familiares mientras éstos lloraban a sus muertos. Los niños que actuaban como familiares de los muertos prefirieron ignorar a los periodistas, simplemente. El tal reportero se despidió diciendo: "Lo que pasa en el Naya se ve en CARACOL Noticias". Yerson le indicó a un niño que personificaba a un familiar que debía gritarles “ipar de mercantiles!”.

Otros niños representaron a funcionarios que llegaban para hacer "el levantamiento de los muertos" y de forma espontánea una niña les corrigió, "muertos no, jvíctimas!". Personificaron mujeres que lloraban y gritaban, ¡"mi esposo!”, “¡mi papá!”, “¡mi hermano”, “¡mi tío”!, otra no encontraba a su familiar. Yerson les indicaba cómo llorar y gritar. En un momento exclamó, “¡no se rían, niños!, estamos manifestando una expresión de nuestra historia!”. 
Intervino entonces Leandro, el director de la escuela. Es nasa, oriundo de un territorio del norte del Cauca, tiene 44 años. Creó el programa de educación bilingüe que hace parte del programa de educación del CRIC. Es hablante de nasa yuwe y tiene una larga experiencia como profesor. Él mismo es autor de un texto de 13 páginas, "Causas y orígenes de la masacre del Naya", que está recogido en una de las varias publicaciones sobre la masacre y en Internet, pero sin darle crédito por su autoría, nos contó. El texto de Leandro es una cronología del paso de los paramilitares por el Naya en el 2001. Mientras los niños ensayaban, Leandro escribió en el tablero: 1 . Desplazamiento; 2 . Albergue $1 ; 3$. Albergue $2 ; 4$. Proceso de educación propia. Son los pasos que según él hay que representar en la puesta en escena, y pone énfasis en el último punto, la educación propia.

El primer acto finalizó con el arribo de los refugiados al pueblo de Timba. El segundo relató la experiencia de los primeros días en ese poblado, la angustia, la ansiedad y la improvisación de "cambuches"13 para dormir. Luego, la llegada de amenazas al albergue y la decisión de la gran mayoría de irse hasta otro pueblo, Santander de Quilichao, en busca de mayor seguridad. “¿En qué chiva nos montamos?”, recitó una niña. Al grupo inicial se fueron sumando más. “¡Gloria! ¿tú?” - gritó una niña que fungía de mujer a otra que le respondió, “isoy una viuda!”.

De nuevo intervino Leandro en el ensayo, esta vez sobre la presencia del raspachín en la primera escena: no le parecía adecuado que se mostrara el diario vivir en el Naya asociado a la coca. Más bien pongan "colinos ${ }^{14}$ de plátano", dijo. También deben incluir en la huída a más personas negras, agregó. Y en lo del albergue de Timba, "deben añadir que se recibió una declaración de amenaza de los paramilitares" quienes estaban presentes por entonces en ese el pueblo. Los que escenifican no parecen prestarle mucha atención en ese momento. Pero él insistió en que en la última fase de la representación hay que mostrar que "se está consolidando un plan de vida desde un concepto propio". También propuso que los niños leyeran un texto breve en nasa yuwe y en español al inicio de la presentación.

Para el montaje del segundo acto, Yerson empleó la misma estrategia que utilizó en el primer acto. "Niños", exclamó, "recordemos cómo estuvimos en la Plaza de Toros [de Santander de Quilichao] y cómo en Tóez [otro centro de refugio]. ¿Quién nos quiere compartir sobre esto? ¡Eso no se puede olvidar!”. Un niño se animó, "la gente vivía en cambuches, en carpas". "Indios, nos llamaban”, agrega Yerson, quien siguió, "había dos luchas, una frente al mundo exterior, los habitantes de Santander y Toez que nos veían como invasores y nos discriminaban, y la otra, al interior de nosotros mismos, en que luchábamos contra las consecuencias que nos trajo el desplazamiento: la pérdida de familiares, de tierras, de casas y los conflictos que se dieron entre nosotros". Una niña intervino para decirle: 
"en Toez primero nos prestaron unas casitas y nos dieron comida. Pero ya luego no, cada uno respondía. Llegó una ayuda que para hacer carpas, para que desocupáramos las casas". "Las carpas eran amarillas", agrega el maestro Leandro, "las carpas nos enfermaron, nos pusimos amarillos como las carpas. Los que podían pagar arriendo se quedaron en las casas, los que no, ¡a las carpas! Hacía mucho calor. Había mucha discriminación hacia uno, nos decían 'desplazados'”.

Después de un breve receso los niños volvieron muy animados a poner en escena la vida de los albergues: gritaban las "necesidades”: “زalimento, medicina, servicios públicos, trabajo, vivienda, cupos en las escuelas!”. Representaron la fila larguísima para el único baño existente en la Plaza de Toros de Santander, representaron roces entre las mujeres por la pérdida de la ropa y por el agua, por la limpieza del baño y por la manera en que cocinaban las mujeres. En los campamentos los niños se aburrían y peleaban, había hambre y enfermedades.

Yerson decidió entonces, en forma espontánea, contar su "proceso". Dijo que cuando la masacre él no estaba en el Naya, sino que había salido a la ciudad de Cali por unos días. Después de enterarse de los hechos, se fue a vivir en el albergue que se había armado en la Plaza de Toros de Santander. "En Santander yo empecé un proceso con los niños y los jóvenes". "Cuando llegué a Santander sentía rabia por lo que había pasado. Con la masacre perdí mi empleo y todo lo que tenía. Sentía ganas de salir corriendo y volver a comenzar lejos. Entonces, una vez vi a un que niño tenía una pelotica de trapo y jugaba con su hermano; con furia pateaban la pelota contra la pared de la Plaza de Toros mientras gritaban “ejeee”, una exclamación muy del Naya. Les pregunté y dijeron que jugaban "la melea”. Vi a esos niños jugando con la pelota de trapo y a otros que hacían las cosas con miedo; los vi como niños nómades, que estaban deambulando, y como mi hermano es motivador, decidí reunirlos. Les pregunté qué querían hacer y uno dijo que quería crecer, meterse a la guerrilla y vengarse de los paramilitares. Me acordé de la pelota y empecé un proceso con el deporte. Fue un proceso largo, pero valió la pena, aprendimos a jugar fútbol y participábamos en los campeonatos de Santander. Al principio nos iba mal, nos llamaban el equipo de desplazados".

Continuó el ensayo con el tercer y último acto, el de la reorganización y traslado a la finca La Laguna, en Timbío. Los niños trajeron ropas para la ocasión y escogieron la música para cada escena. El acto comenzó con el desorden de la vida en los campamentos y en medio de una discusión algunos hablan de "organizarse". Aparece entonces como personaje el actual gobernador del cabildo, "Don Enrique", quien invita a todos a una reunión. Él había sido inspector de policía ${ }^{15}$ en el Naya, donde tenía tierras de las que lo habían expulsado la guerrilla poco tiempo antes de la masacre, pero no había abandonado la región cuando la irrupción paramilitar. Enrique se crió en el vecindario del resguardo de Jambaló, de abuelo indígena y padre no indígena. Llegó al Naya como muchos otros campesinos, en busca de 
trabajo en las fincas que se abrían en los años ochenta con el impulso de la siembra de coca. Con el tiempo prosperó, logró su propia tierra y se hizo a un liderazgo comunitario después de actuar como inspector de policía. Se ganó la animadversión de la guerrilla por no acatar sus disposiciones.

Los niños actores imitaron su voz fuerte y su manera recia de hablar. Los niños exclamaron, sueltas, las palabras “comité, asociación, grupo, organización” y la decisión de conformar una "asociación de desplazados". Colocaron entonces la intervención de un te'wala, quien habló de la necesidad de pedirle ayuda a la Asociación de Cabildos Indígenas del Norte del Cauca - ACIN y de cómo así la organización tomó la forma de asociación de campesinos e indígenas. Los niños mostraron entonces a los líderes que decidieron interponer una acción de tutela; todos firmaron varios papeles con la esperanza de que una nueva tierra les fuera adjudicada. De pronto el mensajero, esta vez con buenas noticias, comunicó que habían ganado la tutela y que se les entregaría tierra en el municipio de Timbio. La puesta en escena culminó con la llegada de las familias a la finca La Laguna, donde representaron la adecuación de la tierra, las nuevas viviendas y la escuela. El ensayo terminó con una misma exclamación de todos: “¡se vive se siente, el Naya está presente!”.

Esa noche realizaron en la escuela una reunión convocada por el Cabildo Kitek Kiwe. Se hicieron presentes también los directivos de la Asociación ASOCAIDENA. Estuvo un número grande de personas, hombres y mujeres. Discutieron pormenorizadamente la posición que llevarían a la conmemoración y decidieron quiénes debían hablar: Lisinia, el gobernador del Cabildo y el presidente de la Asociación. Al poco, Leandro pidió discutir la aparición del "raspachín" en el sociodrama y manifestó su abierto desacuerdo: es inconveniente como imagen pública, es algo "político", dijo. Yerson, en contrario, arguyó que los niños debían aprender que raspar coca no era malo, sino que lo hacían "por necesidad" y "que eso tiene que ver con el abandono del Estado". Varios polemizaron. La decisión: el "raspachín" debe salir de escena, porque quienes verán el sociodrama en Timba no van a entenderlo bien. En la discusión salió a la luz la marcada ambivalencia sobre la coca y sobre el Naya: por un lado, la coca permite ingresos altos, "es por necesidad", pero por la otra, la coca fue la causa de que los jóvenes no quisieran estudiar y se "acostumbraran a la plata". Este salón de la escuela tiene las paredes pintadas con dibujos de una mochila que representa el fogón, que es la fuente de la vida según los Nasa. Está pintada una gran hoja de coca como planta sagrada Nasa. También hay varios dibujos hechos por los niños que muestran el río Naya rodeado de palmeras, en un paisaje muy verde, florido, de vivos colores. "Allá todo se daba sin fertilizantes", dijo un asistente a la reunión. "El clima era cálido, no la lluvia y el frío de aqui", anotó otro. Pero está el peligro "de los grupos y sus arbitrariedades". "No tenemos que pensar más en el Naya”, repiten, pero también "somos Naya”.Y "somos Naya” es lo que gritaron los niños el viernes, a la entrada de Timba. 


\section{Timba: Kitek Kiwe puesta en escena}

Los niños siguen de pie en el escenario en el salón de la conmemoración en Timba. Yerson se pasea por él. Los organizadores deciden empezar el acto y leen un largo orden del día. El alcalde de Buenos Aires, al que pertenece el pueblo de Timba, inicia desde la parte baja del salón y pide un aplauso para los niños del escenario: ellos agitan los bastones. De nuevo gritan "se vive, se siente, el Naya está presente" y todos aplauden. El alcalde destaca el acuerdo con la Comisión de Reparación para el proyecto piloto de "reconstrucción" de Buenos Aires, presentes en la mesa directiva del evento. Viene un "acto ecuménico", que consiste en el saludo de representantes de varias iglesias, la católica, la Congregación Israelita del Nuevo Pacto Universal, Lisinia, en nombre de la Iglesia Cristiana Bethesda. Vestida de rojo, eleva su voz, "Nosotros, como víctimas, creemos en lo que creamos. ¡Necesitamos justicia!”. Lee un versículo de la Biblia, es breve y precisa. Le siguen un rosario de representantes de las organizaciones comunitarias, varios de ellos negros. Sigue Enrique, como gobernador del Cabildo Kitek Kiwe: "hablamos como víctimas, hablamos como indígenas", "nos interesa seguir haciendo presencia en el Naya, porque nos pertenece por derecho propio; tenemos cerca de ochenta años allí y porque allí están enterrados los ombligos de nuestros hijos". "Vamos a hacer una denuncia, el Plan Piloto que se hará en Buenos Aires no incluye a los del Naya [...]. Estamos vivitos y coleando y como indígenas pedimos derechos ancestrales [sobre el Naya]". Los aplausos lo interrumpen. Añade la denuncia por la muerte reciente de unos jóvenes en el Naya. Resulta extraño para nosotros su énfasis en el Naya y nos parece que está de nuevo presente la ambigüedad entre la nueva tierra en una nueva comunidad y la tierra de la que fueron obligados a huir.

Después de los representantes de las juntas comunales del Naya, interviene un directivo del CRIC. En un largo, pausado y bien estructurado discurso que comienza en nasa yuwe, dice "este evento es de las víctimas; que no sea un espacio para legitimar actos resolutorios del gobierno". Saluda "con buenos ojos" la iniciativa de "reconstrucción" de Buenos Aires, pero se enfoca contra la Ley de Justicia y Paz y las políticas del gobierno sobre la reparación de víctimas. Son las víctimas, dice, las que se han movido para evitar un recorte de la verdad; hay que avanzar en la judicialización de los victimarios, de todos ellos, recalca. Ahora Jorge, de Kitek Kiwe, habla a nombre, no del cabildo, sino de ASOCAIDENA. Se detiene en la demanda que la Asociación colocó contra el Estado pidiendo indemnización colectiva y en las fallas de la ley de Justicia y Paz, en lo inconveniente del decreto de reparación individual por vía administrativa (Decreto 1290 de 2008), y de la falta de garantías de "no repetición" de actos de violencia. Vienen varias intervenciones, una mujer negra, maestra al parecer, lee un texto escrito con cuidado, que enfatiza la diversidad cultural de las víctimas. 
Han pasado ya varias horas. Hace mucho calor en el recinto, las personas se dispersan y agitan. Los niños, parece increíble, siguen en el escenario, inquietos, en movimiento, ipero en el escenario! Nos preguntamos si habrá sociodrama, pues faltan varias intervenciones, entre ellas las del delegado de la Comisión de Reparación. El ambiente es de sopor. De repente Lisinia, al parecer sin que estuviera previsto, pues no la han anunciado en el orden del día, habla. Sube el tono de la voz, agudo, alto, muy alto, “¿Dónde están las víctimas?, ¿Se durmieron?”. En efecto, todos parecen despertar y se sacude el público con esta mujer pequeña. El énfasis de la intervención de Lisinia es "no callar", denunciar que la fuerza pública fue cómplice de la masacre y que el Estado tiene que "reparar". "Queremos florecer de nuevo y lo queremos hacer en conjunto, en comunidad”, concluye.

En el momento de la masacre Lisinia vivía sobre el camino del Naya. Ella es una de las hijas de una familia Nasa que migró al Naya en busca de tierra en los cincuenta. Trabajaba junto con su marido, indígena, en un restaurante para los viajeros. Uno de los días de la masacre toda la familia, en la que había tres niños, fue retenida por el grupo "paramilitar" en su propia casa; allí escucharon el asesinato de varias personas que los paramilitares apresaban en el camino e incluso oyeron el ruido de motosierras con las que dieron muerte a una pareja de campesinos acusados de apoyar la guerrilla. Ella perdió entonces el sentido y cayó desmayada. Ya entrada la tarde, el comandante del grupo que los retenía llamó a su esposo diciéndole, "camine señor nos ayuda a llevar esta mula y más tardecito vuelve". No volvió en la noche. Al otro día Lisinia y sus hijos recibieron la noticia de que él también había sido asesinado.

Durante el desplazamiento, Lisinia habitó en los campamentos de refugiados de Toez, Cauca. De esa primera época ella recuerda que se encerró en su casa y no quería hablar con nadie, ni siquiera con sus hijos y hermanas: "a mi no me gustaba hablar con nadie, menos del tema de la masacre, no aceptaba que eso hubiera pasado; la gente, sobre todo la gente con acento costeño, negra o afro, me daba miedo, como esos "paracos" habían venido de la costa y pues eran así, morenos, yo no podía ver a un negro o oír a un costeño por que salía corriendo para mi casa”. No obstante su encierro, cuando los refugiados de Santander de Quilichao decidieron conformar ASOCAIDENA, nombraron a Lisinia cabeza de la organización porque representaba a las "viudas del Naya". "Yo acepté, y ahí fue cuando me tocó ir de seguido a Santander, traía las noticias y tenía que comunicárselas a toda la comunidad desplazada en Toez. Fue entonces cómo, sin proponérmelo, comencé a hablar otra vez con la gente. Vea usted, ¡quien iba a pensar que trabajar en la organización de la comunidad me iba a servir para aceptar lo que me pasó, perder el miedo y querer seguir adelante!”.

Después de Lisinia sigue una lectura larga de denuncias y peticiones al gobierno, poco se escucha y suena bastante forzado. Decae de nuevo el ánimo. Nada del sociodrama. Un rumor de conversación - las personas cansadas hablan entre sí - apaga alguna intervención. No habrá sociodrama, comentamos con Ángela, 
pero por lo menos filmamos los ensayos, dijimos. De pronto Leandro se une a los niños en el escenario, lee un texto breve que comienza "Cuando sea grande voy a volver al Naya...”. Cuando terminó Leandro, Yerson se tomó el escenario y arrancó con el sociodrama. El público se sacudió, eran como las 2 de la tarde. Todos se interesaron al ver a los niños en acción: ahora se marcan más las escenas pero los diálogos poco se escuchan. Yerson, con entonación de locutor, hace de relator y cobra el protagonismo, con micrófono en mano. En esta versión tiene mucho mayor énfasis la última escena del sociodrama: la solución es la organización, es ASOCAIDENA, es el Cabildo Kitek Kiwe, es la acción de tutela que les dio "el territorio" de La Laguna. "De minga en minga, de trabajo comunitario en trabajo comunitario, de asamblea en asamblea se lucha por la vida”, gritó Yerson, y "Les regalamos un mensaje final: exigimos verdad, justicia y reparación y derecho a no repetición”. El público, emocionado, aplaudió y muchos se salieron cuando el sociodrama terminó, pese a que el delegado de la Comisión Nacional de Reparación, empezó, "la verdad se construye entre todos...". La sala se vació casi por completo. También nosotros salimos.

Esta versión es distinta a la del ensayo, más breve y mucho más "política", de denuncia. Pero es innegable que los de Kitek Kiwe logaron imprimirle el sello indígena a la conmemoración y opacaron las otras intervenciones. Los de Kitek Kiwe le dieron el tono emocional al evento. Es claro para nosotros que la categoría de "víctimas", de víctimas que quieren verdad y justicia, envuelve y define el sentido del acto, mientras la reparación oficial queda como a la defensiva. La conmemoración completa fue marcada por el uso emblemático de la etnicidad india: bastones de mando, banderas y pancartas, lengua nasa yuwe, el sociodrama, presencia organizada y considerablemente más visible que la afro. El impacto lo han puesto sin duda los de Kitek Kiwe y los medios (TELEPACÍFICO, CARACOL, prensa) lo amplifican.

Volvemos a las chivas. No más oscurece en la carretera e instalan música de cumbias villeras y reguetón: la chiva se transforma en una discoteca o bailadero de los jóvenes, mientras los niños cansados duermen. Cuando llegamos, la casa de Lisinia está encendida en luz verde. El hijo mayor tiene la TV encendida. "Vengan" nos dice, "estamos desde hace rato en la televisión, han pasado la conmemoración, sacaron a los niños, a los dirigentes". Lisinia llegó hasta el otro día, se ríe, "el acto fue de nosotros, las víctimas".

\section{Comentarios finales}

La séptima conmemoración de la masacre ocurrida en el Naya, en el 2001, fue una oportunidad para que las comunidades del Naya, y en particular la de Kitek Kiwe, le exhibieran a un público heterogéneo una narrativa escénica que ofrece su propia versión de la masacre. Anclada en la condición de "víctimas" indígenas 
que reclaman por lo sufrido, la escenificación de la conmemoración propuso una interpretación de los hechos que aspira a generalizarse más allá de los límites estrechos de una comunidad étnica en particular. Fue también una interpelación interna: hacia la diversidad de pobladores del Naya - indígenas y afrocolombianos, comerciantes, cultivadores de coca, grupos armados que allí existen - y hacia la población regional negra e indígena y sus organizaciones.

Los elementos puestos escena por parte de los dirigentes de las distintas organizaciones de campesinos y afro descendientes fueron en especial el recurso de la denuncia de los atropellos y la invocación a la paz, incluso por la vía del ecumenismo religioso. No obstante, todo esto quedó subsumido por el tono emocional de la etnicidad india que auspiciaron Kitek Kiwe y el CRIC. En especial los asistentes, tan diversos como fueron, se vieron convocados por los niños de Kitek Kiwe, por su dramatización de los sucesos, la que fue hábilmente resaltada mediante la combinación de discursos articulados de reclamo y denuncia de tres de sus dirigentes, uno de ellos una mujer de palabra vivaz. Los reforzaron los himnos, estribillos y enunciados en nasa yuwe y español y las enormes pancartas, en cuyo centro estaba el estandarte rojo y verde del CRIC: "Unidad, Tierra y Cultura". Es posible que la mayoría de los asistentes desconociera que los cinco bastones de mando encintados que rodean este lema del CRIC representan a los pueblos ${ }^{16}$ del Cauca que se unieron en 1971 para fundar la organización indígena. También que ignoren que los bastones o "chontas" aluden a un símbolo central de la autoridad indígena, el símbolo de la autoridad del shamán o te'wala como mediador de las fuerzas espirituales vitales y que es quien avala la autoridad de los reunidos en cabildo. Pero aunque no lo sepan, se estremecieron emocionados cada vez que los niños agitaban en alto sus bastones mientras entonaban en nasa yuwe el himno nacional, de manera que se le transmitió a otros el significado de su situación social, justamente lo que para Alexander (Op. cit.) define la puesta en escena como acción social.

El contenido del relato escénico, en contraste, creó una narrativa con una cronología de sucesos particulares y un relato del sufrimiento que los actos de violencia causaron y cómo lucharon las personas para sobreponerse. Los que sufrieron tomaron el rostro de una mujer hecha "viuda", de una niña que no quería dejar su muñeca, los que caían en un recorrido atropellado, descalzos, a tumbos en la noche, un te'wala como mensajero que los guía. De los albergues sin agua, del tedio y el miedo. Y finalmente, vino la recomposición por medio de la organización "propia", como indígenas, y la construcción de "un plan de vida propio". Así, el relato adquiere tono emocional en torno de la categoría de "víctima indígena". Una víctima que mira, cuenta, actúa, reclama, no sólo se queja. Se hace posible así un proceso de extensión cultural que se expande desde el guión y el actor hasta la audiencia, mediante un proceso de identificación psicológica. Pero lo que es particular aquí es la heterogeneidad cultural en la que transcurre el relato escénico y la capacidad para comunicar esferas socioculturales distintas. 
El acto estuvo enmarcado por la política cultural que han puesto en marcha las organizaciones indias en Colombia desde hace más de tres décadas como una manera de enunciar los reclamos por el reconocimiento del derecho a la diferencia. La invocación a "lo propio" es algo más que esencialización táctica o estratégica. Es un lenguaje intercultural articulado, en el cual las comunidades indias se dirigen al poder establecido y, al mismo tiempo, le hablan a un conjunto mucho más amplio que puede identificarse con ellos y apoyar sus reclamos frente al Estado. Para que esto sea posible, construyen referentes simples que proveen el bagaje necesario para tejer representaciones colectivas: la escenificación se organiza con marcadores sencillos que afirman una indianeidad orgullosa: lengua indígena, invocación a la autoridad "propia", reclamo por la tierra, que sirven para relevar la denuncia de los atropellos y hacer visible el dolor de las víctimas. La puesta en escena apuntala una comunidad emocional por medio de lazos de empatía con el dolor de las víctimas, y es allí donde se unen el dolor subjetivo con la acción colectiva y la particularidad cultural con la interculturalidad. En este contexto, el uso y reafirmación "de lo que nos es propio" trasciende el sentido de "ser diferente es legítimo", puesto que al emplear los marcadores de diferencia y reafirmar la etnicidad india, se logra involucrar emocionalmente a los no indios. La vía escénica es pues la creación de comunidad emocional donde la diferencia es la posibilidad de encuentro y no de separación. Lo indígena se revela como un campo activo de producción cultural de imágenes, modelos, ideales. Sobre todo de ideales para todos, generalizables a colombianos en su construcción de una ciudadanía sensible a la diferencia.

\section{Notas}

1. Véanse Defensoría del Pueblo, 2001; Luz Piedad Caicedo, Daniel Manrique, Constanza Millán \& Mary Pulido, 2006; Humberto Cárdenas Mota \& Consejo Comunitario río Naya, 2005; Pedro García \& Efraín Jaramillo, 2008.

2. Sobre el número de víctimas resultantes de la masacre hay discrepancias. La Defensoría del Pueblo reconoce un total de 40 personas asesinadas (Defensoría del Pueblo, 2001a); se han encontrado 38 cadáveres, pero la comunidad asegura que fueron más de 100 las víctimas. El Vicepresidente de la República, Francisco Santos, en una alocución realizada en Ginebra durante la 61 Sesión de la Comisión de Derechos Humanos de Naciones Unidas, dijo que "en la masacre del río Naya (Cauca) ocurrida el 14 de abril del 2001 las AUC asesinaron 130 personas" (Santos, 2005. Todos contra el terrorismo. Alocución delVicepresidente de la República en la 61 Sesión de la Comisión de Derechos Humanos de Naciones Unidas, marzo 16 de 2005. Disponible en: http://www.vicepresidencia.gov.co/prueba/ discursos/ddhh16032004.htm [septiembre 2005]). 
3. Defensoría del Pueblo. 2001. Resolución defensorial No. 009, sobre la situación de orden público en la región del río Naya. Bogotá, 9 de Mayo de 2001.

4. El Ministerio del Interior y de Justicia de Colombia registró, en el año 2007, 8.150 familias indígenas inscritas como población desplazada. Entre el año 1999 y el 2005 sufrieron 7 masacres a manos, ora de paramilitares o de guerrillas de izquierda. En diciembre de 2008 fue muerto a manos del Ejército colombiano el esposo de la presidenta del CRIC, por el supuesto de no acatar una orden de detener su carro. Pero esto fue visto como una terrible retaliación por las marchas indígenas que llegaron con sus demandas hasta la capital, en noviembre de ese año. Sobre la situación de derechos humanos, véase Osorio \& Salazar (2006) y la página del CRIC http:/ / www.cric-colombia.org.

5. Buses locales caracterizados por su abigarrada decoración.

6. Comisión oficial encargada de poner en marcha la Ley 975 de 2005, Ley de Justicia y Paz.

7. Para las fricciones entre indígenas y población negra, ver Ng' weno, 2001.

8. Relató la hermana de Elías Trochez que el ELN asesinó al líder indígena después de un viaje a Bogotá, donde él pidió ayuda de instituciones del Estado por el cerco de abastecimientos del Naya impuesto por grupos paramilitares; él también alertó con tiempo sobre los planes paramilitares de atacar al Naya. Pero la guerrilla no estuvo de acuerdo con su viaje, pues implicaba la intervención estatal. En ese momento eran agudas las tensiones entre los grupos de guerrilla ELN y FARC y los pobladores locales por sus intentos de control de la zona. La guerrilla veía como rivales a las organizaciones comunitarias campesinas e indígenas que les disputaban el control de la población (entrevistas de campo y Caicedo et al, 2006). Ya habían impuesto "sanciones", incluso el destierro y la expropiación de sus fincas, a algunos dirigentes cívicos y habían amenazado al gobernador indígena si desobedecía.

9. Álvaro Uribe, presidente de Colombia.

10. Palabra nasa yuwe para el shamán.

11. Denominación coloquial para los que trabajan en la recolección de la hoja de coca para su procesamiento en cocaína.

12. Dirigente del resguardo indígena llamado Cerro Tijeras, con gran ascendiente en el Naya en ese entonces.

13. Toldos de tela plastificada, y también se designa así a las carpas que proporcionaron organismos humanitarios.

14. Plantas pequeñas de plátano.

15. Persona encargada de los asuntos locales de policía.

16. Paes o nasa, guambiano, coconuco, totoró, yanacona. En la actualidad, se han agregado tres pueblos más: epirara- siapirara, ingano y guanaco. 


\section{Referências bibliográficas}

ALEXANDER, Jeffrey. 2006. "Cultural pragmatics: social performance between ritual and strategy". In: et al. (ed.). Social Performance. Symbolic Action, Cultural pragmatics, and Ritual. Cambridge, New York: Cambridge University Press. pp. 29-90.

CAICEDO, Luz Piedad; MANRIQUE, Daniel; MILLÁN, Constanza \& PULIDO, Mary. 2006. Desplazamiento y retorno. Balance de una política. Libro 3: El limbo en la tierra. Reubicación de la población desplazada del Alto Naya en Timbío, Cauca. Bogota: Instituto Latinoamericano de Servicios Legales Alternativos (ILSA).

CÁRDENAS MOTA, Humberto \& CONSEJO COMUNITARIO RÍO NAYA. 2005. Gramática de la barbarie. Bogotá: Asociación de Trabajo Interdisciplinario ATI.

CHÁVEZ CHAMORRO, Margarita. 1998. "Identidad y representación entre indígenas y colonos de la amazonía colombiana”. In: María Lucía Sotomayor (ed.). Modernidad identidad y desarrollo. Bogotá: ICANH-COLCIENCIAS.

DE SOUSA SANTOS, Boaventura. 2002. “Toward a Multicultural Conception of Human Rights”. In: Berta Hernández-Truyol (ed.). Moral Imperialism. A critical Anthology. New York: New York University Press. pp. 39-60.

DIAZ LOPEZ, Zamira. 1994. Oro, sociedad y economia. El sistema colonial en la gobernación de Popayan: 1533-1733. Bogotá: Banco de la Republica.

DIETZ, Gunther. 2007. "Multiculturalismo. Un breviario para el debate”. Revista La Palabra y el Hombre (Revista de la Universidad Veracruzana), pp. 38-42, México, Octubre-Diciembre.

GARCÍA, Pedro \& JARAMILlO, Efraín. 2008. Colombia: El caso del Naya. Bogotá: IWGIA, Colectivo de Trabajo Jenzera, Informe 2 IWGIA.

GROS, Christian. 1991. Colombia indígena. Identidad cultural y cambio social. Bogotá: CEREC.

JACKSON, Jean. 2005. “Colombia's Indigenous Peoples Confront the Armed Conflict”. In: Cristina Rojas \& Judit Meltzer (eds.). Elusive Peace: International, National and Local. Dimensions of Conflict in Colombia. New York: Palgrave, MacMillan. pp. 185-208.

JIMENO, Myriam. 2008. "Lenguaje, subjetividad y experiencias de violencia". In: Francisco Ortega (ed.). Veena Das: Sujetos de dolor, agentes de dignidad. Bogotá: Instituto Pensar, Javeriana University, Colección CES, National University of Colombia, Faculty of Human Sciences and Economics, National University of Colombia, Medellín. pp.: 261-291. 2006. Juan Gregorio Palechor: historia de mi vida. Bogotá: Universidad Nacional de Colombia, Centro de Estudios Sociales CES/CRIC/ ICANH/ Universidad del Cauca. 
2004. "El indigenismo como espejo de la nación”. Comentario al texto "Los dilemas del pluralismo brasileño de Alcida Ramos”. Revista Maguaré, 18:26-32, Departamento de Antropología Universidad Nacional de Colombia.

en prensa "Reforma constitucional en Colombia y pueblos indígenas. Los límites de la ley”. In: Alcida Ramos (comp.). Brasília: Universidad de Brasilia y Fundación Ford (en prensa).

\& TRIANA, Adolfo. 1985. Estado y minorías étnicas en Colombia. Bogotá: Ediciones Cuadernos del Jaguar,

KYMLICKA, Will. 1995. Ciudadanía Multicultural. Barcelona: Editorial Paidós.

LAURENT, Virginie. 2005. Comunidades indígenas, espacios políticos y movilización electoral en Colombia, 1990-1998. Bogotá: Instituto Colombiano de Antropología e Historia ICANH e Instituto Francés de Estudios Andinos IFEA.

MOSQUERA, Gilma \& GNISET, Jacques Aprile. 2001. "Hábitats y sociedades del Pacifico. Vol. 3: Aldeas de la costa de Buenaventura”. Cali: Universidad del Valle.

NG'WENO, BETTINA. 2005. “'Vuelvan a África'; 'Me voy para África aun cuando sea en una foto': África y la identidad afrocolombiana en el norte del Cauca”.In: Joanne Rappaport (ed.). Retornando la Mirada: una Investigación Colaborativa, Interetnica sobre el Cauca a la Entrada del Milenio. Popayán: Editorial Universidad del Cauca. pp. 119-127.

OSORIO, Luis Carlos \& SALAZAR, Francisco. 2006. Derechos Humanos y pueblos indígenas en Colombia. Bogotá: Fundación Hemera y Programa Presidencial de Derechos Humanos.

RAMOS, Alcida. 1998. Indigenism. Ethnic Politics in Brazil. Madison: The University of Wisconsin Press.

RAPPAPORT, Joanne. 2005a. Intercultural Utopias. Public Intellectuals, Cultural Experimentation and Ethnic Pluralism in Colombia. Durham and London: Duke University Pres.

. 2005b. Retornando la mirada: una investigación colaborativa interétnica sobre el Cauca a la entrada del milenio. Bogotá: Editorial Universidad del Cauca.

. \& GOW, David D. 1997. "Cambio dirigido, movimiento indígena y estereotipos del indio: el Estado colombiano y la reubicación de los nasa. In: María Victoria Uribe \& Eduardo Restrepo (eds). Antropología en la modernidad. Bogotá: Instituto Colombiano de Antropología. pp. 361-399.

SAHLINS, Marshall. 2001. "Dos o tres cosas que sé acerca del concepto de cultura”. Revista Colombiana de Antropología, v. 37:291-327, Enero-Diciembre.

STAVENHAGEN, Rodolfo. 2002. "Los derechos indígenas. Algunos problemas conceptúales”. In: Carlos Vladimir Zambrano (ed.). Etnopolíticas y racismo. Conflictividad y desafíos interculturales en América Latina. Bogotá: Universidad Nacional de Colombia, Facultad de Derecho, Ciencias Políticas y Sociales. pp. 151-173. 
WIEVIORKA, Michel. 2003. "Diferencias culturales, racismo y democracia”. In: Daniel Mato (coord.). Políticas de identidades y diferencias sociales en tiempos de globalización. Caracas: FACES - UCV. pp. 17-32.

\section{Fuentes documentales}

DEFENSORÍA DEL PUEBLO. 2001. Resolución defensorial No. 009, sobre la situación de orden público en la región del río Naya. Bogotá: Ministerio del Interior y de Justicia, República de Colombia, 9 de Mayo de 2001. www. Mininteriorjusticia.gov.co, 02-26- 2007.

MINISTERIO del INTERIOR. 1998. Los pueblos indígenas en el país en América. Elementos de política nacional e internacional. Bogotá: Dirección General de Asuntos Indígenas.

SANTOS, Francisco. 2005. Todos contra el terrorismo. Alocución del Vicepresidente de la República en la 61 Sesión de la Comisión de Derechos Humanos de Naciones Unidas, marzo 16 de 2005. Disponible en: http:/ /www.vicepresidencia.gov.co/prueba/ discursos/ ddhh16032004.htm [septiembre 2005]). 


\section{Resumen}

Recientemente se cumplieron siete años del acto de violencia conocido en Colombia como la masacre del Naya, en el que murieron a manos de "paramilitares" al menos cuarenta pobladores nasa, afrocolombianos, campesinos y comerciantes de esa región remota del sur occidente colombiano.

Este texto estudia la narrativa escénica con la que uno de los grupos de supervivientes - la comunidad Kitek Kiwe - recreó lo sucedido al conmemorarse siete años. La puesta en escena nos permite discutir los mecanismos y procesos en los que la política cultural alienta la recomposición emocional y política después de un hecho de violencia de gran magnitud. La narrativa escénica pone en evidencia matices, énfasis y juegos de sentido y cómo los emplean las personas para recobrarse como sujetos y crear comunidades emocionales interculturales que trasciendan sus fronteras étnicas y culturales.

\section{Palavras-chave}

Comunidades emocionales, performance, política cultural, memoria, violencia

\begin{abstract}
Colombia recently marked the seventh anniversary of an extended act of violence known as the Naya massacre. At least forty people were killed in this paramilitary massacre in a remote area of southwestern Colombia known as the Upper Naya. The dead included Nasa Indians, Afro-Colombians, mestizo peasants, and local merchants.

This text examines the narrative performance which one of the organized groups of survivors known as the Kitek Kiwe community used to represent the event at its seven-year commemoration. A consideration of their performance gives us an opportunity to discuss the mechanisms and processes by which cultural politics contribute to emotional and political recovery after a large-scale act of violence. The performance exposed the use of nuances, emphases, and plays on meaning that people use to recover their identity as subjects and create intercultural emotional communities that transcend ethnic and cultural boundaries.
\end{abstract}

\section{Key words}

Emotional communities, performance, cultural politics, memory, violence. 